\title{
Bioatividade de três espécies vegetais nativas da Floresta Atlântica brasileira frente ao microcrustáceo Artemia salina
}

\section{POMPILHO, W.M1, ${ }^{*}$; MARCONDES, H.C ${ }^{3} ;$ OLIVEIRA, T.T'1.}

'Universidade Federal de Viçosa, Departamento de Bioquímica e Biologia Molecular, DBB. Av. PH. Holfs, s/n Centro. Viçosa, MG - Brasil. CEP: 36571-000. e-mail: ttoledo@ufv.br; 2Universidade Federal Fluminense, Polo Universitário de Volta Redonda, Departamento de Química. Rua Desembargador Ellis Hermydio Figueira, 783, Bairro Aterrado. Volta Redonda, RJ - Brasil. CEP: 27213-415. e-mail: wendel_bio@puvr.uff.br; ${ }^{3}$ Universidade Federal de Ouro Preto, Instituto de Ciências Exatas e Biológicas, DQui. Campus Universitário-Morro do Cruzeiro - ICEB II - Lab.11. Ouro Preto, MG - Brasil. CEP: 35400-000. e-mail: helciocassemiro@yahoo.com.br . *autor para correspondência

\begin{abstract}
RESUMO: Este trabalho teve por objetivo a investigação fitoquímica e propriedades antioxidantes de extratos das folhas de Trigynaea oblongifolia Schltdl (Annonaceae), Ottonia frutescens Trel (Piperaceae), e Bathysa australis (St Hill) Hooz (Rubiaceae), bem como avaliar, in vitro, a letalidade frente ao microcrustáceo Artemia salina Leach. Os extratos foram preparados por maceração em metanol $10 \%(\mathrm{p} / \mathrm{v})$ por sete dias, à temperatura ambiente. A atividade antioxidante dos extratos foi determinada pela metodologia que utiliza o radical estável DPPH. A toxicidade dos extratos foi avaliada frente ao microcrustáceo $A$. salina. Os extratos de $O$. frutescens e $B$. australis apresentaram as seguintes classes de metabólitos secundários: Alcalóides, Antraquinonas, Cumarinas, Polifenóis (Taninos), Saponinas. Nos extratos de T. oblongifolia, além dos metabólitos citados anteriormente, foi detectada a presença de Flavonóides. A atividade antioxidante, observada em 30 minutos na concentração de $24 \mu \mathrm{g} / \mathrm{mL}$ de extrato, foi de: $O$. frutescens - 38,3\%, T. oblongifolia - 32,3\%, e B. australis - 32,1\%. A Concentração Letal, $\mathrm{CL}_{50}$, dos extratos em $A$. salina foi de: $O$. frutescens $-149,75 \pm 1,02 \mu \mathrm{g} / \mathrm{mL}, T$. oblongifolia - 148,8 \pm $1,74 \mu \mathrm{g} / \mathrm{mL}$, e $B$. australis $-684 \pm 9,04 \mu \mathrm{g} / \mathrm{mL}$. Neste contexto, destacamos as espécies, nativas da Floresta Atlântica, O. frutescens e T. oblongifolia de grande potencial na bioprospecção de moléculas biologicamente ativas.
\end{abstract}

Palavras-Chave: Artemia salina, Bioprospecção, Atividade Antioxidante, Floresta Atlântica.

\begin{abstract}
Bioactivity of three plant species native to the Brazilian Atlantic Forest front of microcrustacean Artemia salina. This study aimed to carry out phytochemical and antioxidant properties, and assess, in vitro, the lethality of a leaf extract Trigynaea Schltdl oblongifolia Schltdl (Annonaceae), Ottonia frutescens Trel (Piperaceae), Bathysa australis (St Hill) Hooz (Rubiaceae) front of the microcrustaceans Artemia salina Leach. Extracts were prepared by soaking in $10 \%$ methanol $(\mathrm{w} / \mathrm{v})$ for seven days at room temperature. The antioxidant activity of extracts was determined by the stable radical DPPH method. The toxicity of the extracts was evaluated against the microcrustaceans $A$. saline. Extracts of $O$. frutescens and $B$. australis showed the following classes of secondary metabolites: Alkaloid, Anthraquinones, Coumarins, polyphenols (tannins), Saponin. The extracts from T. oblongifolia, besides the aforementioned metabolites the presence of flavonoids was detected. The antioxidant activity was observed in 30 minutes, the concentration $24 \mathrm{mg} / \mathrm{mL}$ of extract was: $O$. frutescens $-38.3 \%, T$ oblongifolia - $32.3 \%$, and $B$. australis $-32.1 \%$. The lethal concentration, $L_{50}$, extracts of $A$. salina was: $O$. frutescens - $149.75 \pm 1.02 \mathrm{mg} / \mathrm{mL}$, T. oblongifolia - $148.8 \pm 1.74 \mathrm{mg} / \mathrm{mL}$, and $B$. australis $-684 \pm$ $9.04 \mathrm{mg} / \mathrm{mL}$. In this context, we highlight the species, native to the Atlantic Forest, $O$. frutescens and $T$. oblongifolia great potential in bioprospecting of biologically active molecules.
\end{abstract}

Keywords: Artemia salina, Bioprospecting, Antioxidant Activity, Atlantic Forest.

Recebido para publicação em 09/10/2012

Aceito para publicação em 27/02/2014

10.1590/1983-084X/12_148

Rev. Bras. PI. Med., Campinas, v.16, n.3, p.473-480, 2014. 


\section{INTRODUÇÃO}

Artemia salina é um microcrustáceo de água salgado utilizado como alimento para peixes ornamentais. Os ovos deste microcrustáceo apresentam elevada taxa de eclosão e são facilmente encontrados em lojas especializadas em aquários. Os náupilos deste microcrustáceo são utilizados para estimar a toxicidade através da concentração letal $\left(\mathrm{CL}_{50}\right)$ e os resultados podem ser tratados estatisticamente com facilidade (Meyer et al. 1982).

O ensaio de letalidade com $A$. salina permite a avaliação da toxicidade geral, sendo considerado essencial como bioensaio preliminar no estudo de compostos com potencial atividade biológica (Parra et al. 2001). Diversos trabalhos correlacionam a toxicidade sobre $A$. salina com atividades, antifúngica, virucida, antimicrobiana, antiparasitária, tripanossomicida (Moreira et al. 2003; Noldin et al. 2003; Zuque et al. 2004). Este bioensaio tem sido muito utilizado na avaliação prévia de extratos de plantas com possível propriedade antitumoral (Garcez et al. 2005; Ngoumfo et al. 2010; ElMenshawi et al. 2010).

Abusca por produtos naturais biologicamente ativos é um desafio enfrentado por vários grupos de pesquisa e diversos laboratórios espalhados pelo mundo. Nesse contexto, estão os vegetais como fonte de moléculas bioativas devido ao seu metabolismo secundário (Simões et al. 2007).

No Brasil, as fontes de moléculas biologicamente ativas estão disponíveis em abundância em sua megadiversidade biológica. $\mathrm{O}$ bioma Floresta Atlântica com, aproximadamente, 15.700 espécies vegetais das quais 7.155 são endêmicas (aproximadamente 40\% de endemismo) (Stehmann et al. 2009), é uma fonte inesgotável de produtos naturais.

Ao longo dos anos um elevado número de moléculas de origem vegetal é avaliado quanto à sua atividade biológica, em vários modelos experimentais, dentre eles a $A$. salina. Isso resultou no surgimento de várias drogas efetivas no tratamento de inúmeras patologias (Ramakrishna et al. 1984). Um bom exemplo de tal fato são os fármacos utilizados no combate ao câncer, os quais incluem produtos naturais puros ou modificações semissintéticas de material natural, dos quais destacamos: vimblastina (Velban $\left.{ }^{\circledR}\right)$ e vincristina (Oncovin ${ }^{\circledR}$ ) e seus análogos vindesina (Eldisine ${ }^{\circledR}$ ) e vinorelbina (Navelbine $\left.{ }^{\circledR}\right)$; o paclitaxel (Taxol$\left.{ }^{\circledR}\right)$ e o análogo docetaxel (Taxotere ${ }^{\circledR}$ ); a podofilotoxina e os análogos, etoposídeo (Etopophos ${ }^{\circledR}$ ) e teniposídeo (Vumon ${ }^{\circledR}$ ); e a camptotecinae e os análogos, topotecano (Hycamtin ${ }^{\circledR}$ ) e irinotecano (Camptosar ${ }^{\circledR}$ ). Aproximadamente, $60 \%$ dos fármacos anticâncer introduzida na terapêutica nas últimas décadas tem sua origem nos produtos naturais (Mukherjee et al. 2001).

Para execução deste trabalho, foram selecionadas três espécies dentre a imensa diversidade biológica da Floresta Atlântica, a saber: Trigynaea oblongifolia Schltdl (Annonaceae), Ottonia frutescens Trel (Piperaceae) e Bathysa australis (St Hill) Hooz (Rubiaceae). A seleção de tais espécies teve como base análise da literatura, na qual foram constatados relatos de atividade biológica em indivíduos pertencentes a essas famílias (Nakamura et al. 2006; Silva et al. 2007; Figueiredo et al. 2009).

O presente estudo teve como objetivo realizar investigação fitoquímica, propriedade antioxidante, e avaliação in vitro da atividade citotóxica de extratos metanólicos de folhas das três espécies supracitadas frente ao microcrustáceo Artemia salina Leach.

\section{MATERIAL E MÉTODO}

Área de coleta do material botânico

O material botânico foi coletado no fragmento de Floresta Atlântica encontrado na fazenda Santa Rita, situada na Bacia Hidrográfica do Rio Paraíba do Sul, na Zona da Mata Leste do Estado de Minas Gerais. Esta fazenda localiza-se entre os municípios de Carangola e Faria Lemos $\left(20^{\circ} 46^{\prime} \mathrm{S}\right.$ e $\left.42^{\circ} 02^{\prime} \mathrm{W}\right)$. Os desníveis altimétricos da fazenda variam entre 500 e 750 metros. O solo é representado pelos tipos Cambissolos, Latossolos e Podzólicos. A temperatura anual varia de $16^{\circ} \mathrm{C}$ a $28^{\circ} \mathrm{C}$ e pluviosidade média anual de $2.268 \mathrm{~mm}$. A vegetação local é reconhecida como Floresta Ombrófila Densa (Leoni, 2002).

A coleta de material vegetal nos fragmentos florestais foi feita sob a forma de caminhada aleatória, adentrando-se pelo fragmento florestal e em suas bordas.

\section{Material Botânico}

Folhas de indivíduos adultos de Trigynaea oblongifolia Schltdl (ANNONACEAE), Ottonia frutescens Trel (PIPERACEAE), Bathysa australis (St Hill) Hooz (RUBIACEAE) foram coletadas com o auxílio de tesoura de poda. Amostras testemunhas estão depositadas no herbário "Guido Pabst" - GFJP no Município de Itaperuna RJ, sob os números de registro 943 GFJP (T. oblongifolia), 204 GFJP (O. frutescens), e 1749 GFJP (B. australis).

\section{Preparação do Extrato Vegetal}

Folhas de T. oblongifolia, O. frutescens, e $B$. australis foram submetidas à secagem em estufa de ventilação forçada, sob temperatura constante 
de $40^{\circ} \mathrm{C}$ até estabilização do peso; dessa forma foi obtido a matéria seca para cada um dos materiais supracitados.

O material desidratado foi mergulhado em pequenas quantidades de nitrogênio líquido para congelar rapidamente; após o congelamento as amostras foram trituradas, separadamente em gral e pistilo. Neste procedimento foram utilizadas $350 \mathrm{~g}$ de folhas de $O$. frutescens; $850 \mathrm{~g}$ de $T$. oblongifolia, e $900 \mathrm{~g}$ de $B$. australis. O material com granulometria reduzida foi depositado em um frasco âmbar e submetido a extração por maceração em metanol $10 \%(\mathrm{p} / \mathrm{v})$ por sete dias, à temperatura ambiente. O período para a extração exaustiva foi de 21 dias. A cada sete dias, o líquido extrator foi filtrado e novo líquido extrator foi adicionado. $O$ extrato obtido foi concentrado em evaporador rotativo sob temperatura controlada entre $40^{\circ} \mathrm{C}$ e $50^{\circ} \mathrm{C}$. $O$ processo de secagem do extrato das folhas foi finalizado sob ventilação direta, com temperatura controlada entre $40^{\circ} \mathrm{C}$ e $50^{\circ} \mathrm{C}$, dando origem ao material seco. Verificou-se o rendimento dos extratos e, em seguida, foram armazenados em recipiente plástico opaco em presença de agente dessecante.

\section{Prospecção fitoquímica dos extratos}

Aanálise fitoquímica dos extratos metanólicos das folhas de O. frutescens, T. oblongifolia, e $B$. australis foi realizada em cromatografia em camada delgada (CCD) (Wagner et al. 1984). Foi avaliada a presença dos seguintes grupos de metabólitos secundários: Alcalóides, Antraquinonas, Cardiotônicos, Cumarinas, Flavonóides, Polifenóis (Taninos), Saponinas, Triterpenos.

No processo cromatográfico foram usadas as fases móveis, reveladores, e padrões de referência específicos para cada uma das classes de metabólitos secundários (Tabela 1) (Wagner et al. 1984).

\section{Avaliação da atividade antioxidante pelo teste do DPPH}

A capacidade de eliminar radicais livres dos três extratos foi determinada utilizando o radical estável DPPH (2,2-diphenyl-1-picrylhydrazyl). Nessa metodologia, caso o extrato tenha compostos com propriedade antioxidante, esse reage com o DPPH, reduzindo-o. Esta redução resulta na mudança de coloração, de violeta para amarelo claro (Silva et al. 1999; Sousa et al. 2007).

As amostras foram diluídas em metanol em cinco diferentes concentrações, a saber: $30,60,120$, $180,240 \mu \mathrm{g} / \mathrm{mL}$. Foram adicionados $300 \mu \mathrm{L}$ de cada uma das cinco concentrações das três amostras em 2,7 $\mathrm{mL}$ de solução metanólica de DPPH a $60 \mu \mathrm{M}$. A concentração final das amostras foi de $3,6,12,18$, $24 \mu \mathrm{g} / \mathrm{mL}$.
A solução de DPPH foi preparada diariamente, armazenada ao abrigo da luz, e mantida a $4^{\circ} \mathrm{C}$ até o momento da utilização.

O controle foi preparado da seguinte forma: 2,7 mL da solução metanólica de DPPH acrescidos de $300 \mu \mathrm{L}$ de metanol. Para o controle (branco) foram preparadas cinco soluções, ou seja, uma para cada concentração de extrato. O preparo dessas soluções deu-se da seguinte forma: 300 $\mu \mathrm{L}$ de amostra (concentração: $30,60,120,180$, $240 \mu \mathrm{g} / \mathrm{mL}$ ) foram diluídos em $2,7 \mathrm{~mL}$ de metanol. A concentração final dos controles foi de $3,6,12$, $18,24 \mu \mathrm{g} / \mathrm{mL}$.

O meio da reação foi mantido ao abrigo da luz à temperatura ambiente. A absorbância das amostras foi medida nos tempos: zero, 15,30 e 45 minutos; o comprimento de onda usado foi de $515 \mathrm{~nm}$ em cubetas de quartzo. A atividade antioxidante da amostra, em porcentagem de captação do DPPH, foi calculada em relação à absorbância do controle (maior absorbância) e à absorbância da solução contendo a amostra, através da fórmula:

$\% A A=\frac{A B S \text { controle }-(\text { ABSamostra }- \text { ABSbranco })}{A B S \text { controle }} \times 100$

Foi calculada a $\mathrm{CL}_{50}$ para o experimento utilizando o programa GraphPad Prism versão 5,0 por meio de curva de regressão não linear, a partir dos dados obtidos no experimento. $\mathrm{A} \mathrm{CL}_{50}$ é a concentração necessária para que o extrato testado reduza em $50 \%$ a concentração de DPPH utilizada.

\section{Ensaio de toxicidade com Artemia salina}

O ensaio de toxicidade dos extratos adaptado do método descrito por Meyer et al. (1982) utilizando o microcrustáceo Artemia salina Leach.

Os extratos de $O$. frutescens, T. oblongifolia e $B$. australis foram dissolvidos em solução de Dimetil sulfoxido - DMSO 2,5\% e água marinha sintética.

Ovos de Artemia salina, adquiridos comercialmente, foram colocados em um béquer contendo uma solução de sal marinho (38g/L), $\mathrm{pH}$ 8; essa solução foi denominada água marinha sintética. Foi utilizado um borbulhador para manter a solução em agitação constante. A temperatura foi mantida entre $20^{\circ} \mathrm{C}$ a $25^{\circ} \mathrm{C}$ em banho-maria. Após 24 horas os ovos de $A$. salina eclodiram em náupilos.

Em microplacas de 96 poços foram preparadas concentrações de 1, 10, 50, 100, 200, 400,800 e $1000 \mu \mathrm{g} / \mathrm{mL}$ para cada um dos extratos e a cada uma delas foram adicionados 10 náupilos do microcrustáceo, e novamente incubadas em banho-maria $\left(20^{\circ} \mathrm{C}\right.$ a $\left.25^{\circ} \mathrm{C}\right)$ por 24 horas.

Após esse período, o número de microcrustáceos vivos e mortos em cada 
Tabela 1. Prospecção fitoquímica dos extratos etanólicos das folhas de Ottonia frutescens, Trigynaea oblongifolia e Bathysa australis.

\begin{tabular}{|c|c|c|c|}
\hline Classe de metabólito & Fase móvel & Revelador & Padrão \\
\hline Alcalóides & $\begin{array}{l}\text { Acetato de etila-metanol-água } \\
\qquad(100: 14: 10)\end{array}$ & Reagente de Dragendorff & Quinina \\
\hline Antraquinonas & $\begin{array}{l}\text { Acetato de etila-metanol-água } \\
\qquad(100: 17: 13)\end{array}$ & $\begin{array}{c}\text { Solução KOH } 5 \% \text { em } \\
\text { etanol }\end{array}$ & 1,8-diidroxiantraquinona \\
\hline Cardiotônicos & $\begin{array}{l}\text { Acetato de etila-metanol-água } \\
\qquad(81: 11: 8)\end{array}$ & Reagente de Kedde & Digitoxina \\
\hline Cumarinas & $\begin{array}{l}\text { Ácido acético-tolueno-éter dietílico- } \\
\text { água (50:25:25:5) }\end{array}$ & $\begin{array}{c}\text { Solução } \mathrm{KOH} 5 \% \text { em } \\
\text { etanol }\end{array}$ & Benzopirona \\
\hline Flavonóides & $\begin{array}{l}\text { Acetato de etila-ácido-fórmico-ácido } \\
\text { acético-água (55:5:5:1) }\end{array}$ & $\begin{array}{c}\text { Solução } \mathrm{AlCl}_{2} 5 \% \text { em } \\
\text { etanol }\end{array}$ & Rutina \\
\hline Polifenóis (Taninos) & $\begin{array}{l}\text { Tolueno-butanol-ácido acético } \\
\qquad(80: 40: 16)\end{array}$ & Reagente de Barton & Ácido pirogálico \\
\hline Saponinas & $\begin{array}{l}\text { Clorofórmio-ácido acético glacial- } \\
\text { metanol-água (15:8:3:2) }\end{array}$ & Anisaldeído sulfúrioco & 18- $\beta$-glicírretínico \\
\hline
\end{tabular}

concentração foi contado com auxílio de um estereoscópio binocular E. Leitz Wetzlar (20 vezes). Foram consideradas mortas aquelas larvas que permaneceram imóveis por mais de 10 segundos. O ensaio foi realizado em triplicata.

Como controle positivo foi utilizada uma solução de dicromato de potássio nas concentrações de 400,600 e $800 \mathrm{~g} / \mathrm{mL}$ e, para controle negativo, 200 $\mu \mathrm{L}$ de água marinha. Foi acrescentado controle com DMSO 2,5\%. O experimento foi validado somente quando nos controles positivos foi observada a morte e, no controle negativo, a sobrevivência de todos os indivíduos.

Para cálculo da $\mathrm{CL}_{50}$, utilizou-se o método de Probitos de análise, que é definido como a concentração necessária para causar a morte de $50 \%$ das larvas de Artemia salina no período de 24 horas.

Os cálculos foram realizados no programa computacional estatístico "MICRO PROBIT". Com confiança de $95 \%$.

Os compostos foram considerados altamente tóxicos quando a $\mathrm{CL}_{50}$ foi menor que $80 \mu \mathrm{g} /$ $\mathrm{mL}$; entre $80 \mu \mathrm{g} / \mathrm{mL}$ e $250 \mu \mathrm{g} / \mathrm{mL}$ foram considerados moderadamente tóxicos; e com $\mathrm{CL}_{50}$ maior que 250 $\mu \mathrm{g} / \mathrm{mL}$, com baixa toxicidade ou não tóxicos (Parra et al. 2001).

\section{Análise estatística}

Os resultados foram expressos por média \pm desvio padrão, analisados de forma independente. Os ensaios foram analisados por ANOVA- One-way - seguido de aplicação do teste Tukey utilizando o programa Graph Pad versão 5.0. As diferenças significativas foram consideradas como $p<0,05$, $p<0,01$ e $p<0,001$.

\section{RESULTADOS E DISCUSSÃO}

Inicialmente foi realizado o processo de secagem do material coletado. Segundo Hansen et al. (1993), a secagem de plantas tem por objetivo retirar uma porcentagem elevada de água livre das células e dos tecidos, impedindo os processos de degradação enzimática e garantindo a preservação do princípio ativo.

A tabela 2 revela os valores encontrados para matéria verde coletada no campo, teor de água, matéria seca obtida e rendimento do extrato para cada uma das três espécies estudadas. O rendimento dos extratos foi calculado em relação à quantidade do material vegetal seco utilizado na extração. 
Tabela 2. Rendimento do material botânico (folhas).

\begin{tabular}{lllll}
\hline Nome da Espécie & Matéria Verde & Teor de Água (\%) & Matéria Seca & Rendimento do Extrato (\%) \\
\hline Ottonia frutescens & $350 \mathrm{~g}$ & 68,58 & $110 \mathrm{~g}$ & $5,39 \mathrm{~g}(4,90)$ \\
Trigynaea oblongifolia & $850 \mathrm{~g}$ & 81,40 & $158 \mathrm{~g}$ & $7,86 \mathrm{~g}(4,98)$ \\
Bathysa australis & $900 \mathrm{~g}$ & 81,67 & $165 \mathrm{~g}$ & $6,68 \mathrm{~g}(4,05)$ \\
\hline
\end{tabular}

A partir do material seco foram preparados os extratos em metanol. É importante ressaltar que fatores tais como: a fertilidade e o tipo do solo, a umidade, a radiação solar, o vento, a temperatura e a poluição atmosférica podem influenciar na composição química dos vegetais, bem como as interações e as adaptações coevolutivas do ecossistema envolvido (Simões et al. 2007).

Nesse sentido, o extrato de folhas de uma única espécie vegetal pode conter diversas moléculas estruturalmente diferentes, e, ainda, pertencentes a várias classes de metabólitos secundários (Simões et al. 2007). A prospecção fitoquímica dos extratos metanólicos das folhas de O. frutescens, $T$. oblongifolia e $B$. australis está apresentada na tabela 3 .

Apesar de pertencerem a grupos taxonômicos diferentes, as três espécies avaliadas apresentaram composição fitoquímica semelhante em relação às principais classes de metabólitos secundários. Foram observadas as seguintes classes de moléculas: alcalóides, Antraquinonas, Polifenóis (Taninos), e Saponina. Não foi detectada a presença de Cardiotônicos em nenhuma das três espécies. A presença de flavonóides foi detectada apenas no extrato de T. oblongifolia. Ficou constatada a ausência dos metabólitos cardiotônicos e triterpeno em todos os extratos.

Nesse trabalho obtivemos apenas informações sobre as classes de metabólitos secundários, porém, a literatura revela um vasto conjunto de informações sobre a ação antitumoral, por exemplo, de várias moléculas representantes das classes encontradas nas três espécies estudadas.

Neste sentido, podemos citar os alcalóides vimblastina e vincristina que são drogas antimitóticas, as quais são amplamente utilizadas no tratamento do câncer (Mann, 2002).

Segundo Reynolds \& Dweck, (1999) a antraquinona aloe-emodina encontrada nas folhas de Aloe vera (Liliaceae), espécie popularmente conhecida como Babosa, é capaz de promover apoptose e inibição do crescimento de células tumorais.

A partir do Calophyllum brasiliense (Clusiaceae) (Guanandi) foram isoladas três cumarinas que apresentaram propriedade antitumoral (Ruiz-Marcial et al. 2007). Segundo Ito et al. (2006) as cumarinas calophyllolide e mammea B/BB induzem apoptose em células de linhagem leucêmica (HL-60).

Dados da literatura evidenciam que os compostos fenólicos atuam na supressão do crescimento de células tumorais, por induzir a apoptose (Loa et al. 2009). Os compostos polifenólicos são amplamente distribuídos nas folhas e casca dos frutos; o resveratrol é um bom exemplo de polifenol (Creasy \& Coffee, 1988). O resveratrol pode inibir metástases, angiogênese, induzir apoptose, causar parada do ciclo celular, e senescência em diversos tumores (Heiss et al. 2007).

A propriedade antitumoral de diversas saponinas, advindas de espécies variadas de plantas, tem sido avaliada em diferentes tipos de

Tabela 3. Resultado da prospecção fitoquímica dos extratos metanólicos das folhas de Ottonia frutescens, Trigynaea oblongifolia, Bathysa australis. (-) negativo e (+) positivo.

\begin{tabular}{llll}
\hline \multirow{2}{*}{ Classe de Metabólito } & \multicolumn{3}{c}{ Nome da Espécie } \\
\cline { 2 - 4 } & Ottonia frutescens & Trigynaea oblongifolia & Bathysa australis \\
\hline Alcalóides & + & + & + \\
Antraquinonas & + & + & + \\
Cardiotônicos & - & - & - \\
Cumarinas & + & + & + \\
Flavonóides & - & + & - \\
Polifenóis (Taninos) & + & + & + \\
Saponinas & + & + & + \\
\hline
\end{tabular}


tumores. Os ginsenosídeos, derivados da planta Panax ginseng (ginseng coreano), são as saponinas mais estudas. Sua atividade sobre a proliferação de células tumorais está relacionada ao controle do ciclo celular e indução de apoptótica (Mujoo et al. 2001).

Como relatado anteriormente, a presença de flavonóides foi detectada apenas no extrato de T. oblongifolia. Segundo Santos \& Salatino (2000) é possível encontrar nas folhas de $T$. oblongifolia os seguintes flavonóides: apigenina, canferol e quercetina.

Por agirem como antioxidantes, apigenina, canferol e quercetina exibem diversos efeitos benéficos à saúde humana, tais como antiinflamatório, antialérgico, e antiviral, bem como, atividade antitumoral (Narayana et al. 2001).

Como observamos nas folhas de $O$. frutescens, $T$. oblongifolia e $B$. australis é possível encontrar classes de moléculas para as quais a literatura apresenta inúmeros representantes com propriedades antiproliferativas. Dessa forma, fica notória a importância de aprofundar o estudo dessas três espécies, com o propósito de verificar suas atividades biológicas.

Moléculas com propriedades antioxidante são de grande importância para os seres vivos, pois em baixas concentrações comparadas às do substrato oxidável (Radicais livres), atrasa ou inibe a oxidação desse substrato de maneira eficaz (Sies, 1993).

Radicais livres são espécies químicas que contém um ou mais pares de elétrons livres. São altamente reativos e instáveis, possuindo vida curta; e sua formação ocorre naturalmente no organismo de todos os seres vivos, devido à exposição ao oxigênio molecular (Smith et al. 1997). São produzidos por modificações químicas de proteínas, lipídios, carboidratos e nucleotídeos, resultando em uma variedade de conseqüências biológicas, incluindo lesão tecidual, mutação, carcinogênese (Kong \& Lillehei, 1998).

Nesse sentido, a atividade antioxidante dos extratos foi confirmada através da técnica de mensuração da taxa de seqüestro do radical livre
DPPH (Tabela 4).

A propriedade antioxidante dos vegetais está relacionada, principalmente, aos compostos fenólicos. Os compostos fenólicos estão disponíveis nas plantas como ácidos fenólicos, flavonóides, lignanas, estilbenos, cumarinas e taninos, os quais podem ser encontrados em todas as partes do vegetal. Os fenóis mais comuns são polímeros e ligninas insolúveis, e, dentre os flavonóides mais encontrados, estão a quercetina e a rutina (Shahidi \& Naczk, 1995).

Como relatado anteriormente, mesmo com atividade positiva para polifenóis e cumarinas nos testes fitoquímicos, os três extratos testados apresentaram atividade antioxidante moderada. A $\mathrm{CL}_{50}$ para os três extratos foi maior que $24 \mu \mathrm{g} / \mathrm{mL}$. Um extrato com alto potencial em seqüestrar radicais livres deve possuir um baixo valor de $\mathrm{CL}_{50}$.

É importante ressaltar que existem alguns fatores que influenciam na capacidade antioxidante dos extratos, tais como: o método de extração utilizado determina a composição química dos extratos, bem como a época em que foi realizada a coleta do material botânico (Bou et al. 2013). Outros fatores importantes a serem considerados são os métodos de avaliação da atividade antioxidante e as concentrações de extrato utilizadas na experimentação. Todos esses fatores podem influenciar nos resultados da capacidade antioxidante de um extrato.

A literatura está repleta de relatos que indicam atividade farmacológica em benefício à saúde humana de várias classes de metabólitos secundários, porém muitos compostos que fazem parte da composição química das plantas podem ser tóxicos, quando ingeridos de forma indiscriminada (Oliveira et al. 2003)

Equivocadamente, a cultura popular acredita que fazer o uso exagerado de determinada planta não causa mal algum, pelo simples fato de ser de origem natural. Nesse contexto, é importante que estudos de toxicidade com plantas medicinais sejam realizados, principalmente avaliando sua ação em nível celular.

Nesse sentido realizamos os testes

Tabela 4. Porcentagem da atividade antioxidante dos extratos metanólicos de folhas de Ottonia frutescens, Trigynaea oblongifolia, Bathysa australis.

\begin{tabular}{lllllc}
\hline \multirow{2}{*}{ Nome da Espécie } & \multicolumn{5}{c}{ Concentração de extrato $(\boldsymbol{\mu g} / \mathbf{m L})$} \\
\cline { 2 - 6 } & \multicolumn{1}{c}{3} & 6 & 12 & 18 & 24 \\
\hline Ottonia frutescens & $2,7 \pm 0,7$ & $9,6 \pm 0,6$ & $12,5 \pm 0,6$ & $31,2 \pm 0,8$ & $38,3 \pm 0,6$ \\
Trigynaea oblongifolia & $14,4 \pm 3,8$ & $16,3 \pm 0,1$ & $19,3 \pm 0,6$ & $24,4 \pm 0,5$ & $32,3 \pm 0,8$ \\
Bathysa australis & $6,2 \pm 0,3$ & $13,1 \pm 0,2$ & $19,9 \pm 0,3$ & $27,6 \pm 0,3$ & $32,1 \pm 0,6$ \\
\hline
\end{tabular}

Observação: Tempo 30 minutos. O valor da média \pm desvio padrão foram obtidos por meio de triplicata

Rev. Bras. Pl. Med., Campinas, v.16, n.3, p.473-480, 2014. 
citotóxicos preliminares em $A$. salina dos extratos de folhas de $O$. frutescens (Figura 1), T. oblongifolia (Figura 2) e B. australis (Figura 3). Ao final do teste foram calculadas as $\mathrm{CL}_{50}$, os extratos de $O$. frutescens e $T$. oblongifolia foram considerados moderadamente tóxicos frente ao teste de toxicidade em A. salina, pois apresentaram $\mathrm{CL}_{50}$ de $149,75 \pm$ $1,02 \mu \mathrm{g} / \mathrm{mL}$ e $148,8 \pm 1,74 \mu \mathrm{g} / \mathrm{mL}$, respectivamente. $O$ extrato de $B$. australis não apresentou resultados de toxicidade significativa frente aos náupilos de $A$. salina, com uma $\mathrm{CL}_{50}$ de $684 \pm 9,04 \mu \mathrm{g} / \mathrm{mL}$.

Os resultados com $A$. salina indicam que os extratos das folhas de $O$. frutescens e $T$. oblongifolia, possivelmente, apresentam moléculas bioativas; porém, essa possibilidade não é válida

\section{Ottonia frutescens}

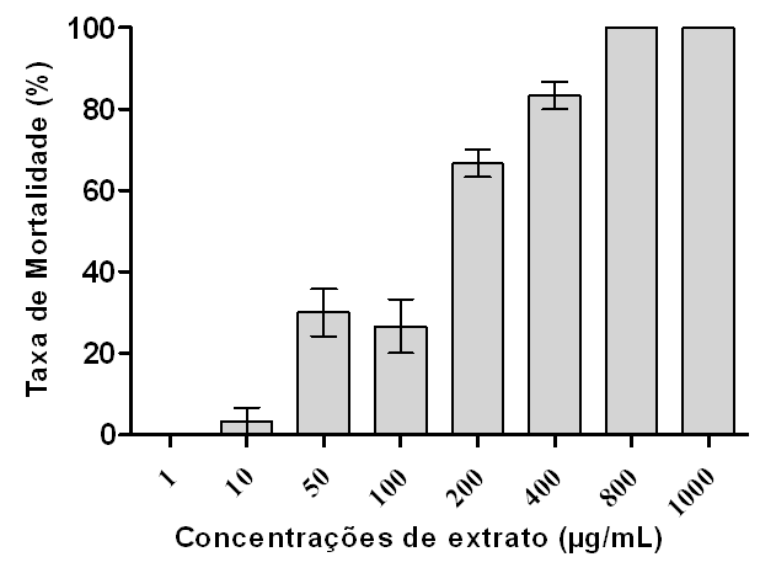

Figura 1. Taxa de mortalidade de náupilos de Artemia salina em função da concentração de extrato Ottonia frutescens.

\section{Trigynaea oblongifolia}

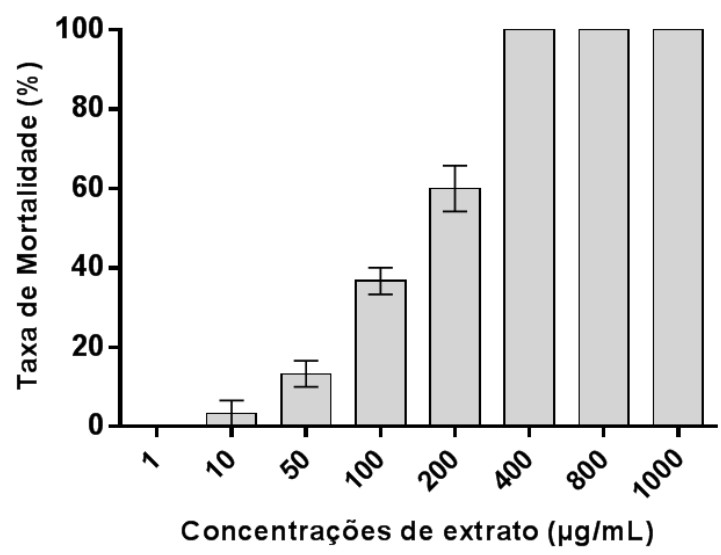

Figura 2. Taxa de mortalidade de náupilos de Artemia salina em função da concentração de extrato Trigyneae oblongifolia.

\section{Trigynaea oblongifolia}

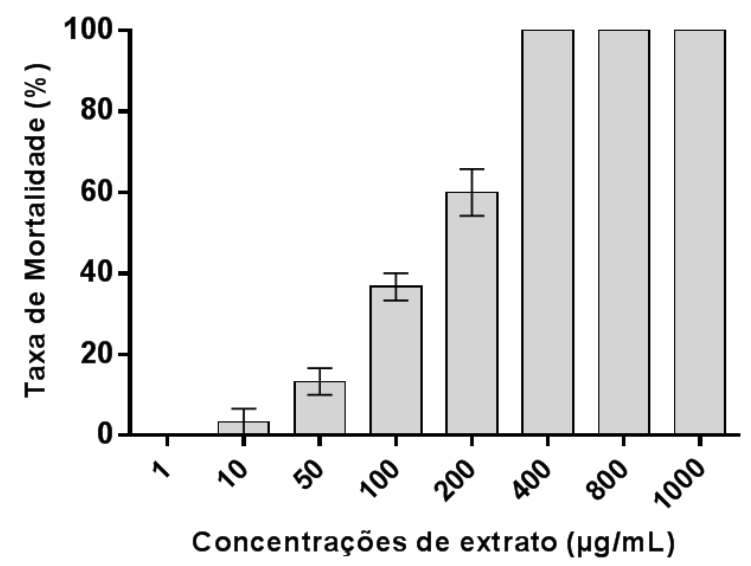

Figura 3. Taxa de mortalidade de náupilos de Artemia salina em função da concentração de extrato Bathysa australis.

para os extratos de $B$. australis. Tal afirmativa tem como base os resultados de outros trabalhos que correlacionam a toxicidade em $A$. salina com atividades biológicas (Moreira et al. 2003; Zuque et al. 2004; Garcez et al. 2005; Ngoumfo et al. 2010; El-Menshawi, et al. 2010).

\section{REFERÊNCIA}

BOU. D.D. et al. Chemical composition and cytotoxicity evaluation of essential oil from leaves of casearia sylvestris, its main compound a-zingiberene and derivatives. Molecules. V.18. n.8, p. 9477-9487, 2013.

CREASY, L.L.; COFFEE, M. Phytoalexin production potential of grape berries. J Am Soc Hortic Sci, v. 113, p. 230-234, 1988.

EL-MENSHAWI, B.S. et al. LINDER, S. Screening of natural products for therapeutic activity against solid tumors. Indian J Exp Biol. V.48, n.3, p. 258-264, 2010.

FIGUEIREDO, A.D.L. et al. Avaliação da atividade antimicrobiana das partes aéreas (folhas e caules) e raízes de Richardia brasiliensis Gomez (Rubiaceae). Rev Ciênc Farm Básica Apl. v.30. n.2, p.193-196, 2009.

GARCEZ, F.R. et al. Cytotoxic and genotoxic butanolides and lignans from Aiouea trinervis. Planta Med. v. 71, n.10, p. 923-7, 2005.

HANSEN, R. C. et al. Thin layer drying of cultivated taxus clippings. Transactions of the ASAE, v. 36, n. 5, p. 1387-1391, 1993.

HEISS, E.H. et al. Chronic treatment with resveratrol induces redox stress and ataxia telangiectasia mutated (ATM) dependent senescence in p53-positive cancer cells. J Biol Chem. v. 282, n. 37, p. 26759-26766, 2007.

ITO, C. et al. Apoptosis inducing activity of 4-substituted coumarins from Calophyllum brasiliense in human 
leukaemia HL-60 cells. Journal of Pharmacy and Pharmacology, v.58, p.975-980, 2006.

KONG, Q., LILLEHEI, K.O. Antioxidant inhibitors for cancer. Med Hypotheses. v.51, p. 405-9. 1998.

LEONI, L.S. Árvores ocorrentes em fragmento na mata da encosta Atlântica no município de Faria Lemos - Minas Gerais, Brasil. Boletim do Herbário "Guido Pabst". v.13. 2002.

LOA, J. et al. Studies of structure-activity relationship on plant polyphenol-induced suppression of human liver cancer cells. Cancer Chemotherapy and Pharmacology. v.63, p. 1007-1016, 2009.

MANN, J. Natural products in cancer chemotherapy: past, present and future. Nature Reviews (Cancer), v.2, p.143-148, 2002.

MEYER, B. N. et al. Brine shrimp: A convenient general bioassay for active plant constituents. Planta Med. v. 45, p. 31-34, 1982.

MOREIRA, F.P.M. et al. Flavonóides e triterpenos de Baccharis pseudotenuifolia - bioatividade sobre Artemia salina. Quim. Nova, v. 26, n. 3, p. 309-311, 2003.

MUJOO, K. et al. Triterpenoid Saponins from Acacia victoriae (Bentham) Decrease Tumor Cell Proliferation and Induce Apoptosis1. Cancer Research, v. 61, n. 14, p. 5486-5490, 2001.

MUKHERJEE, A.K.; et al. Advances in Cancer Therapy with Plant Based Natural Products. Current Medicinal Chemistry, v.8, p. 1467-1486, 2001.

NAKAMURA, C.V et al. Atividade antileishmania do extrato hidroalcoólico e de frações obtidas de folhas de Piper regnellii (Miq.) C. DC. var. pallescens (C. DC.) Yunck. Revista brasileira de farmacognosia. v.16, n.1, p.6166, 2006.

NARAYANA, K.R. et al. Bioflavonoids classification, pharmacological, biochemical effects and therapeutic potential. Indian Journal of Pharmacology, v.33, p. 2-16, 2001.

NGOUMFO, R.M. et al. In vitro cytotoxic activity of isolated acridones alkaloids from Zanthoxylum leprieurii Guill. et Perr. Bioorg Med Chem. v.15, n.18, p. 3601-5, 2010.

NOLDIN, V.F. et al. Composição química e atividades biológicas das folhas de Cynara scolymus $L$. (ALCACHOFRA) cultivada no Brasil. Quim. Nova, v. 26, n. 3, p.331-334, 2003.

OLIVEIRA, R. B. et al., GODOY, S. A. P., COSTA, F. B. Plantas tóxicas: conhecimento e prevenção de acidentes. Ribeirão Preto - SP: Editora Holos, 2003. $64 p$.
PARRA, A.L. et al. Comparative study of the assay of Artemia salina $\mathrm{L}$. and the estimate of the medium lethal dose (LD50 value) in mice, to determine oral acute toxicity of plant extracts. Phytomedicine, v. 8, n. 5, 395-400, 2001.

RAMAKRISHNA, Y. et al. Plants and novel antitumour agents: A review. Indian Drugs, v.21, p. 173-185, 1984.

REYNOLDS T, DWECK A.C. Aloe vera leaf gel: a review update. J. Ethnopharmacol. v.15; p.3-37, 1999.

RUIZ-MARCIAL, C. et al. Antiproliferative, cytotoxic and antitumour activity of coumarins isolated from Calophyllum brasiliense. Journal of Pharmacy and Pharmacology, v.59, p.719-725, 2007.

SANTOS, D.Y.A.C., SALATINO, M.L.F. Foliar flavonoids of Annonaceae from Brazil: taxonomic significance. Phytochemistry. v.55, p. $567-573,2000$.

SHAHIDI, F.; NACZK, M. Food phenolics: sources, chemistry, effect, applications. Pennsylvania: Technomic, 1995.

SIES, H. Strategies of antioxidant defence. Review. European Journal of Biochemistry, Berlin, v.215, n.2, p.213-219, 1993.

SILVA, D.B. et al. Isolamento e avaliação da atividade citotóxica de alguns alcalóides oxaporfínicos obtidos de annonaceae. Quim. Nova, v. 30, n. 8, p. 1809-1812, 2007.

SILVA, F.A.M. et al. Métodos para avaliação do grau de oxidação lipídica e da capacidade antioxidante. Quim. Nova, v. 22(1), p. 94-103, 1999.

SIMÕES, C.M.O (Org.). Farmacognosia: da planta ao medicamento. 6 ed. Ver. Porto Alegre/Florianópolis. Ed. Universidade/UFRGS/Ed. da UFSC, 2007.

SMITH, W.K.; VOLGEMANN T.C.; DELUCIA E.H.; BELL D.T.; SHEPHERD K.A. Leaf form and photosynthesys. BioScience. v. 47, p.785-793, 1997.

SOUSA, C.M.M. et al. Fenóis totais e atividade antioxidante de cinco plantas medicinais. Quim. Nova, v. 30, n. 2, p.351-355, 2007.

STEHMANN, J.R., FORZZA, R., SALINO, A., SOBRAL, M., COSTA, D.P., KAMINO, L.H.Y. 2009. Plantas da Floresta Atlântica. Jardim Botânico do Rio de Janeiro, RJ. 516p.

WAGNER, H.; BLADT, S.; ZGAINSKI, E.M. Plant drug analysis: a thin layer chromatography atlas. $1^{\mathrm{a}} \mathrm{ed}$. Berlim: Springer Verlag. 320p., 1984.

ZUQUE, A.L.F. et al. Avaliação das atividades antioxidante, antimicrobiana e citotóxica de Couepia grandiflora Benth. (Chrysobalanaceae). Revista brasileira de farmacognosia. v.14, n.2, p. 129-136, 2004. 